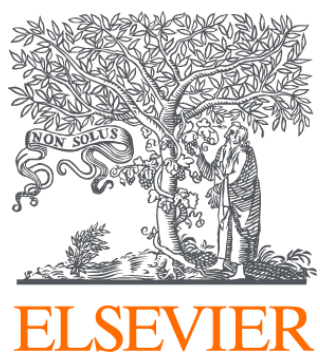

Since January 2020 Elsevier has created a COVID-19 resource centre with free information in English and Mandarin on the novel coronavirus COVID-

19. The COVID-19 resource centre is hosted on Elsevier Connect, the company's public news and information website.

Elsevier hereby grants permission to make all its COVID-19-related research that is available on the COVID-19 resource centre - including this research content - immediately available in PubMed Central and other publicly funded repositories, such as the WHO COVID database with rights for unrestricted research re-use and analyses in any form or by any means with acknowledgement of the original source. These permissions are granted for free by Elsevier for as long as the COVID-19 resource centre remains active. 


\section{Reflections on COVID-19}

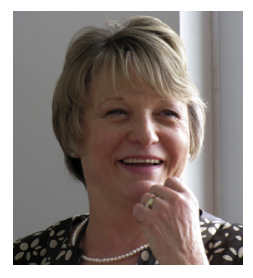

Nancy K. Lowe Editor in Chief am writing this editorial on March 30, 2020. It is a quiet, cool (some would say cold) morning in the mountains of Colorado where I am privileged to live. The sun is coming over the eastern ridge and reflecting off the snow that is awaiting May and perhaps even June to finally melt away for the short Rocky Mountain summer at our altitude of more than 9,000 feet. As I gaze on this pristine view of creation with Pike's Peak in the distance, I am mindful of my many known and unknown professional nursing and midwifery colleagues who continue to labor under the reality of COVID19 and the many individuals who lie in America's hospitals fighting for their lives as human and material resources for their effective care dwindle by the hour.

Two of our own children are physicians, a son in family practice and a daughter in obstetrics and gynecology. In the midst of COVID-19, our son recently lost a patient and dear friend to pancreatic cancer; people continue to deal with and die from other diseases during the pandemic. Our daughter tries to prepare for how to quarantine herself from her husband and young children if she becomes infected with COVID-19 while she goes about her medical responsibilities caring for childbearing women and their infants. Their travel trailer in the driveway may be an option if she needs to quarantine; however, the homeowner's association must approve. Our other son, his wife, and their children live in Washington state where the American story of COVID-19 first became mainstream news. Their children have been very capably homeschooled by their educator mother for many years; hence, their education has not been interrupted. Meanwhile, my husband and I stay "socially isolated" in our home with a view. Life goes on. Birth and death and all the commonalities of life that go between, only they have all changed. For me, a great personal loss during this time is the inability to worship in the company of others each Sunday.

Every day we hear about people who have died from COVID-19 who we may or may not know, whose faces may or may not be familiar due to some degree of celebrity, who may or may not have had some preexisting condition that increased their risk of death. The stories of these individuals touch our hearts and bring great sadness, and, for some, despair. The internet is replete with stories, advice, and information from multiple sources that may or may not be helpful or even accurate. In the midst of the noise come messages of hope, reassurance, and inspiration that feed our souls at a time of national, personal, and professional uncertainty and challenge. Meanwhile those who die in hospitals may be denied the comfort of loved ones, an idea that is unthinkable and goes against every principle of caring for people that we all embrace as health care professionals. If you lose a loved one, a funeral cannot be held, and the bereaved may themselves need to be quarantined and separated from those family and friends who can support them best through their loss.

In New York City, two major private hospital systems, New York Presbyterian and Mt. Sinai Health Systems, closed their doors to even one support person for women during labor and birth. This restriction was despite the New York State Health Department's guidance that a support person for women is essential patient care even in the midst of the COVID-19 pandemic (Hu, 2020). My heart aches and my mind says no, this can't be as I think of women laboring and giving birth alone without the comfort and shared joy of a partner or a significant other. The task before you, my nurse colleagues, to provide this missing support for women is indeed a heavy, critical, but potentially immensely satisfying responsibility. Because I am old enough to have practiced when women labored and/or birthed alone in American hospitals, I can promise you that the privilege of being that nurse for a woman who is alone is amazing and superbly satisfying. Thankfully, due to public outcry, New York's Governor Andrew Cuomo issued an executive order on March 27, 2020, "that required all hospitals in New York, both public and private, to allow women to have a partner in the labor and delivery room-in compliance with the latest guidance from the New York State Department of Health" (Van Syckle \& Caron, 2020). 
By the time this issue of JOGNN is published, we may be over the hump of the current epidemic in the United States, or we may not. Only time will tell. Unfortunately, our public health experts warn that another surge in COVID-19 cases may occur later in the year when flu season typically begins. Perhaps we will be better prepared; perhaps there will be enough personal protective equipment; perhaps there will be enough ventilators; perhaps there will be enough intensive care beds; perhaps there will be a vaccine, although unlikely; perhaps the right antiviral medication will have been developed and be available; perhaps, perhaps. In the meantime, for you, my nurse, midwife, and physician colleagues, I pray for your peace and health, your strength and stamina for the challenges before you professionally and personally, and your protection from illness. I thank you for the dedication, wisdom, and care that you bring to women, their infants, and their families. There is no finer calling.

\section{Check for updates}

\section{REFERENCES}

Hu, L. (2020, March 25). City and private hospitals split on allowing support partners in delivery rooms. Spectrum News. Retrieved from https://www.ny1.com/nyc/all-boroughs/news/2020/03/25/ city-hospitals-to-allow-pregnant-women-in-labor-company-ofsupport-partner-amid-pandemic

Van Syckle, K., \& Caron, C. (2020, March 28). Women will not be forced to be alone when they are giving birth. The New York Times. Retrieved from https://www.nytimes.com/2020/03/28/ parenting/nyc-coronavirus-hospitals-visitors-labor.html 